(2) Open Access Full Text Article

ORIGINALRESEARCH

\title{
Expressed Breast Milk Contamination in Neonatal Intensive Care Unit
}

\author{
Suzan Gad' \\ Mohamed M Sheta ${ }^{2}$ \\ Abeer I Al-khalafawi ${ }^{3}$ \\ Heba A Abu El-Fadl' \\ Maha Anany' \\ Shaimaa Sahmoud' \\ Mona Karem Amin (D) \\ 'Pediatrics and Neonatology \\ Department, Suez Canal University \\ Faculty of Medicine, Ismailia, Egypt; \\ ${ }^{2}$ Pediatrics and Neonatology \\ Department, Mansoura General Hospital, \\ Mansoura, Egypt; ${ }^{3}$ Neonatology \\ Department, Saqr Hospital, MOH, Ras \\ Alkheima, United Arab Emirates
}

Background: The health benefits of breastfeeding are well known. However, some ill babies including those admitted to the neonatal intensive care unit (NICU) cannot be directly breastfed. In this situation, expressed breast milk (EBM) can be used. However, breast milk is not always sterile and may be contaminated by many microorganisms. EBM contamination is probably attributed to improper technical and hygienic factors and may pose significant threats to the newborn baby. The present study aimed to document the prevalence of EBM contamination in NICU and to uncover the relevant risk factors.

Subjects and Methods: The study included 118 mothers who could express breast milk for their own neonates admitted to the NICU. A checklist was used to document the steps the mothers followed during expression of milk and all steps of handling until the EBM reached the NICU. A $1 \mathrm{~mL}$ sample of EBM was obtained and sent to the microbiology laboratory within 20 minutes. Data obtained from the present study are expressed as number and percentage or mean \pm standard deviation (SD). Statistical calculations were computed using SPSS 25.

Results: In the present study, $106(89.8 \%)$ out of the assessed 118 EBM samples were contaminated. Hygienic factors related to EBM contamination included hand only wash, possible recontamination of hands during turning taps off, lack of using cotton pads or cloth piece on nipple and breast cleaning by water only. Other factors related to EBM contamination included container cleaning by water only, fresh milk refrigeration after $>4$ hours, adding freshly expressed warm breast milk to refrigerated milk expressed earlier in the same day, milk transport in plastic bags with ice packs and longer transportation time. In the contaminated samples, the most commonly isolated organisms included Staphylococcus aureus (55.7\%),Staphylococcus epidermidis (21.7\%) and Enterobacter (11.6\%).

Conclusion: The present study identified bacterial contamination in about $90 \%$ of EBM samples delivered to NICU infants. Factors related to EBM contamination include hygienic, storage and transport factors.

Keywords: breastfeeding, expressed breast milk, NICU

\section{Introduction}

Human breast milk is generally considered as the best source of nutrition for newborns and infants. As a worldwide public health recommendation, infants should be exclusively breastfed for the first six months of life to achieve optimal growth, development and health. In preterm infants, feeding with human milk has been found to reduce the rate of infectious complications including late onset sepsis ${ }^{1}$ and necrotizing enterocolitis (NEC). ${ }^{2}$ In addition, use of human milk was associated with better cognitive development at 2
Correspondence: Mohamed M Sheta Pediatrics and Neonatology Department, Mansoura General Hospital, Mansoura, Egypt

Tel +97I-559-865-I66

Email sheta99999@yahoo.com 
years, ${ }^{3}$ lower rate of hospital readmissions and improved cardiovascular outcomes. ${ }^{4,5}$

However, when newborns are admitted to the neonatal intensive care unit (NICU), lactating mothers have to express their breast milk to feed their babies. Because breast milk is not always sterile, microorganisms can multiply when milk is not handled properly. ${ }^{6}$ This may constitute a significant clinical challenge particularly in those vulnerable babies. ${ }^{7}$

Staphylococcus aureus, including MRSA, $\beta$-hemolytic Streptococci, Pseudomonas species, Klebsiella species, Proteus species and Enterobacteria are frequently identified in EBM and may place the infant at risk of infection. ${ }^{8-10}$ Interestingly, Boo et $\mathrm{al}^{11}$ hypothesized increased use of EBM in NICU may be related to increased risk of NEC. They noted that more than $90 \%$ of NEC cases occurred in infants on enteral feeding. Susceptible organisms include Enterobacteria and other gram-positive and gram-negative bacteria. In addition, some reports identified an association between breast milk Enterobacter and neonatal sepsis. ${ }^{12,13}$ Moreover, the study of Mammina et $\mathrm{al}^{14}$ suggested a link between use of EBM in the NICU and nosocomial colonization by imipenem-resistant Pseudomonas aeruginosa.

To increase the percentage of premature newborns who benefit from expressed breast milk (EBM), we need to ensure the appropriate handling of expressed milk till it reaches the baby and to perform bacteriological screening of milk to identify possible pathogens. ${ }^{6}$ Studies assessing the impact of breast expression practices on EBM contamination in the NICU setting shows inconsistent conclusions. $^{15-17}$

The present study aimed to evaluate the steps of maternal handling of EBM leading to the presence of contamination.

\section{Subjects and Methods}

The present study was conducted at Suez Canal University Hospitals in the period from January through December, 2019. The study protocol was approved by the local ethical committee of Faculty of Medicine, Suez Canal University (Ref.103/18) and informed consent was obtained from all participants in accordance with the Declaration of Helsinki on clinical research involving human subjects.

Mothers of preterm neonates consecutively admitted to NICU were included in the study if they could provide sufficient amount of EBM for their own babies. EBM is the human milk obtained through squeezing of the breast either manually or mechanically by aid of pumps. Those who had local breast infection, nipple bleeding or systemic infection were excluded. Before milk expression, experienced nurses instructed all mothers about the appropriate hygiene and technique for manual and pump expression (Comfort Manual breast pump, Philips Avent, England).

A checklist was used to document the steps the mothers followed during expression of milk and handling until the EBM reached the NICU. Once EBM was delivered to the NICU, mothers were asked to fill the checklist to document their hygienic and handling practices.

A sample $(1 \mathrm{~mL})$ of EBM was obtained from every mother and sent to the microbiology laboratory within 20 minutes. In the lab, a sterile swab was taken and cultured on blood and MacConkey agar and incubated for 24-48 hours at $37^{\circ} \mathrm{C}$ temperature. Then, the plates were examined. If bacterial colonies appeared, the quantity of isolated bacteria was counted and gram-stained to identify the type of bacteria. Chemical reactions were used if necessary. Milk samples were defined as contaminated if culture showed $\geq 10^{4}$ staphylococcal cfus $/ \mathrm{mL}$ or any Gramnegative organisms or enterococci. ${ }^{18,19}$ Also, sample was considered contaminated if it contained $\geq 10^{5}$ cfus $/ \mathrm{mL}$ of skin commensals (Staphylococcus epidermidis). ${ }^{20}$

Collected data were analyzed using SPSS statistical software version 23 (IBM, Chicago, USA). Categorical data was expressed as numbers and percentages, while numerical variables were expressed as mean and standard deviation. Categorical variables were compared by chisquare or Fisher's exact test, while numerical variables were compared using student $t$ test. The differences were considered significant when $\mathrm{p}$ value is $<0.05$.

\section{Results}

The present study was conducted on milk samples obtained from 118 mothers of consecutive preterm babies admitted to the NICU. The included mothers had an age of $28.3 \pm 6.9$ years. It was found that 106 samples $(89.8 \%)$ out of the assessed 118 EBM samples were contaminated. Comparison between contaminated and non-contaminated samples revealed significant association between EBM contamination and hygienic behavior. Hygienic factors related to EBM contamination included hand only wash, possible recontamination of hands during turning taps off without, lack of using cotton pads or cloth piece on nipple and breast cleaning by water only (Table 1).

Other factors related to EBM contamination included container cleaning by water only, fresh milk refrigeration after $>4$ hours, adding freshly expressed warm breast milk 
Table I Comparison Between Mothers with Breast Milk Contamination and Mothers without Regarding Hand, Breast and Pump Hygiene

\begin{tabular}{|c|c|c|c|}
\hline & Contaminated EBM n= 106 & Non-Contaminated EBM $n=12$ & $\mathbf{p}$ \\
\hline \multicolumn{4}{|l|}{ Hand hygiene } \\
\hline Finger nails short & $68(64.2)$ & $12(100.0)$ & $0.16 *$ \\
\hline Jewelry removed & $74(69.8)$ & $8(66.7)$ & $0.98^{*}$ \\
\hline Hand wash & $92(86.8)$ & $12(100.0)$ & $0.93 *$ \\
\hline \multicolumn{4}{|l|}{ Hand wash with } \\
\hline - Water only & $44(47.8)$ & $4(33.3)$ & $0.67^{*}$ \\
\hline - Soap and water & $48(52.2)$ & $8(66.7)$ & \\
\hline \multicolumn{4}{|l|}{ Washed parts } \\
\hline - Hand only & $39(84.8)$ & - & $<0.00 I^{*}$ \\
\hline - Hand, under nails and forearms & $7(15.2)$ & $12(100.0)$ & \\
\hline \multicolumn{4}{|l|}{ Tool of hand drying } \\
\hline - Disposable paper towels & $24(26.1)$ & $8(66.7)$ & $0.11 \#$ \\
\hline - Clean cloth towel & $40(43.5)$ & $4(33.3)$ & \\
\hline - No drying & $28(30.4)$ & - & \\
\hline Turning taps off without recontamination of hands & $2(2.2)$ & $6(50.0)$ & $0.003^{*}$ \\
\hline \multicolumn{4}{|l|}{ Breast hygiene } \\
\hline Using cotton pads or cloth piece on nipple & $46(43.4)$ & $12(100.0)$ & $0.011 *$ \\
\hline Breast cleaning & $60(56.7)$ & $2(16.6)$ & $0.09 *$ \\
\hline \multicolumn{4}{|l|}{ Breast cleaning by } \\
\hline - Water only & $32(52.8)$ & - & $0.013 \#$ \\
\hline - Soap and water & $18(30.2)$ & - & \\
\hline - Wipes & $10(17.0)$ & $2(100.0)$ & \\
\hline \multicolumn{4}{|l|}{ Pump hygiene } \\
\hline \multicolumn{4}{|l|}{ Type of expression } \\
\hline - Hands & $40(37.7)$ & $8(66.7)$ & $0.21^{*}$ \\
\hline - Manual breast pump & $66(62.3)$ & $4(33.3)$ & \\
\hline \multicolumn{4}{|l|}{ Pump wash time } \\
\hline - Rinse well in cold water after use & $52(78.8)$ & $4(100.0)$ & $0.3^{*}$ \\
\hline - At end of the day & $14(21.2)$ & - & \\
\hline \multicolumn{4}{|l|}{ Cleaning method } \\
\hline - Water only & $52(78.8)$ & - & $0.061 *$ \\
\hline - Water and liquid soap & $14(21.2)$ & $4(100.0)$ & \\
\hline
\end{tabular}

Notes: Data expressed as number and percent. Statistical analysis was achieved using Fisher's exact test $\left({ }^{*}\right)$ or chi-square test (\#).

to refrigerated milk expressed earlier in the same day, milk transport in plastic bags with ice packs and longer transportation time (Table 2).

In the contaminated samples, the isolated organisms included Staphylococcus aureus $\left(\geq 10^{4}\right.$ cfus $\left./ \mathrm{mL}\right)$ in 59 samples (55.7\%), methicillin-resistant Staphylococcus aureus $\left(\geq 10^{4}\right.$ cfus $\left./ \mathrm{mL}\right)$ in 2 samples (1.9\%) and Staphylococcus epidermidis $\left(>10^{5}\right.$ cfus $\left./ \mathrm{mL}\right)$ in 23 samples (21.7\%). Other isolates included Enterobacter in 12 samples (11.6\%), Actinobacteria in 5 samples (4.7\%), and Klebsiella pneumonia in 5 samples (4.7\%) (Table 3). 
Table 2 Comparison Between Mothers with Breast Milk Contamination and Mothers without Regarding Place of Expression, Milk Container, Storage and Transport Characteristics

\begin{tabular}{|c|c|c|c|}
\hline & $\begin{array}{l}\text { Contaminated } \\
\text { EBM } n=106\end{array}$ & $\begin{array}{l}\text { Non-Contaminated } \\
\text { EBM } n=12\end{array}$ & $\mathbf{p}$ \\
\hline \multicolumn{4}{|l|}{ Place of expression } \\
\hline Home & $68(64.2)$ & $8(66.7)$ & \multirow[t]{2}{*}{$0.98 *$} \\
\hline $\mathrm{NICU}$ & $38(35.8)$ & $4(33.3)$ & \\
\hline \multicolumn{4}{|l|}{ Type of container } \\
\hline Glass & $18(17.0)$ & - & \multirow[t]{3}{*}{$0.76 \#$} \\
\hline Special container for baby food & $78(73.6)$ & $12(100.0)$ & \\
\hline Plastic container designed for general household use & $10(9.4)$ & - & \\
\hline \multicolumn{4}{|l|}{ Container cleaning method } \\
\hline Water only & $68(64.2)$ & - & \multirow[t]{3}{*}{$<0.001 \#$} \\
\hline Water and liquid soap & $22(20.8)$ & - & \\
\hline Boiling & $16(15.1)$ & $12(100.0)$ & \\
\hline \multicolumn{4}{|l|}{ Container drying method } \\
\hline Clean cloth towel & $16(15.1)$ & - & \multirow[t]{3}{*}{$0.76 \#$} \\
\hline Paper tissue & $80(75.5)$ & $12(100.0)$ & \\
\hline None & $10(9.4)$ & - & \\
\hline \multicolumn{4}{|l|}{ Container Storage } \\
\hline Keep in room temp & $72(67.9)$ & $10(83.3)$ & \multirow[t]{2}{*}{$0.66 *$} \\
\hline Keep in refrigerator & $34(32.1)$ & $2(16.7)$ & \\
\hline Need for milk storage & $68(64.2)$ & $8(66.7)$ & $0.98 *$ \\
\hline \multicolumn{4}{|l|}{ Fresh milk refrigeration } \\
\hline Within 4 hrs. & $20(29.4)$ & $8(100.0)$ & \multirow[t]{2}{*}{$0.014^{*}$} \\
\hline$>4$ hrs. & $48(70.6)$ & - & \\
\hline \multicolumn{4}{|l|}{ Duration of fresh milk refrigeration } \\
\hline 48 hrs. & $54(79.4)$ & $8(100.0)$ & \multirow[t]{2}{*}{$0.16 *$} \\
\hline$>48$ hrs. & $14(20.6)$ & - & \\
\hline $\begin{array}{l}\text { Adding freshly expressed warm breast milk to refrigerated milk } \\
\text { expressed earlier in the same day }\end{array}$ & $58(85.3)$ & $2(25.0)$ & $0.024 *$ \\
\hline Cooling milk in the fridge before transporting & $44(66.0)$ & $6(66.7)$ & $0.68 *$ \\
\hline \multicolumn{4}{|l|}{ Milk transport means } \\
\hline Plastic bag with ice packs & $50(74.3)$ & - & \multirow[t]{2}{*}{$0.009 *$} \\
\hline Plastic bag with no ice packs & $18(25.7)$ & $8(100.0)$ & \\
\hline Transportation time (min.) mean \pm SD & $39.4 \pm 16.6$ & $18.8 \pm 7.5$ & $0.013 \S$ \\
\hline
\end{tabular}

Notes: Data expressed as number and percent or mean and standard deviation (SD). Statistical analysis was achieved using Fisher's exact test $(*)$, chi-square test (\#) or $t$ test ( $($ ). 
Table 3 Isolated Microorganisms from Contaminated EBM Samples $(n=106)$

\begin{tabular}{|l|c|}
\hline Isolated Organisms & $\mathbf{n}(\%)$ \\
\hline Staphylococcus aureus & $59(55.7)$ \\
Staphylococcus epidermidis & $23(21.7)$ \\
Methicillin-resistant Staphylococcus aureus & $2(1.9)$ \\
Enterobacter & $12(11.6)$ \\
Actinobacteria & $5(4.7)$ \\
Klebsiella pneumoniae & $5(4.7)$ \\
\hline
\end{tabular}

\section{Discussion}

In the present study, the majority (89.8\%) of EBM samples were contaminated with bacterial growth. The most commonly isolated organisms included Staphylococcus aureus (55.7\%), Staphylococcus epidermidis (21.7\%) and Enterobacter $(11.6 \%)$. In comparison, Karimi et $\mathrm{al}^{15}$ found that $85 \%$ of samples were infected, and dominant microorganisms were Klebsiella (13.7\%) followed by S. epidermidis (12.5\%). In another study, microbiological testing of EBM identified bacterial growth in $75 \%$ of samples. ${ }^{16}$ The relatively high rate of EBM contamination in the present study is attributed to the multiple gaps in the processes of milk expression, storage and transport. It is important to note that in spite of the fact that mothers were instructed about the technical and hygienic aspects of breast milk expression, the compliance rate was not satisfactory. This may be explained by maternal anxiety and stress related to the postpartum period. Also, NICU admission was reported as a risk factor for maternal stress and anxiety. ${ }^{21}$ Another important factor that may contribute to the high rate of EBM is the relatively hot and humid weather in Egypt in most months of the year.

Of note, MRSA was the least prevalent isolated organism in our study group. Interestingly, Behari et $\mathrm{al}^{22}$ found that MRSA can be passed from mother to preterm infant through contaminated breast milk, even in the absence of maternal infection.

In our study, improper hand washing was associated with EBM contamination. This is consistent with the conclusions of Steele, ${ }^{23}$ who noted that hand washing with aseptic techniques is valuable in preservation of bacterial growth to acceptable levels.

Another factor related to EBM contamination is lack of appropriate breast hygiene. In support of these findings, Rodrígue ${ }^{24}$ suggested that maternal breast skin may be the source of breast milk contamination.

EBM contamination may be related to other storage and transport factors. In our work, boiling the containers was significantly associated with less milk contamination. In accordance with these findings, Eglash et $\mathrm{a}^{25}$ recommended boiling infants' feeding items, especially for infants in NICU. Also, we found that bacterial growth was significantly associated with refrigeration of expressed milk after more than 4 hours. Likewise, Ukegbu et $\mathrm{al}^{26}$ found that bacterial load was higher in breast milk samples stored at room temperature for up to 9 hours compared to those immediately refrigerated.

In addition, we found that bacterial growth was significantly associated with mixing the freshly expressed warm breast milk with refrigerated one expressed earlier in the same day. Actually, many studies have indicated that fresh milk should be cooled before adding to cold milk in the fridge and that stored milk should be rotated using first-in-first-out (FIFO) principles with the oldest milk being used first. ${ }^{23}$

Moreover, we noted that the mean transportation time of the contaminated EBM was significantly longer than that of sterile milk. As other studies reported, with both time and varying temperatures, components in human milk are decreased in potency, while the growth of pathogens is increased. $^{25,26}$

Findings of the present study may have significant implications. The study found a high prevalence of EBM contamination. This problem should be addressed by adoption of more strict measures to control transmission of infection. In addition, the study raises concern about the possible hazards related to use of EBM. Probably, there is a need for clear and evidence-based recommendations to guide the care-givers' decisions on use of EBM particularly in vulnerable babies like those admitted to ICU.

The current study reported the Egyptian experience with EBM contamination in the ICU setting and tried to document the relevant risk factors in detail. However, the study is not without limitations. It was conducted at a single center, which limits the generalizability of its findings. Moreover, the study did not assess the relation between EBM contamination and neonatal outcome.

\section{Conclusion}

Conclusively, the present study identified bacterial contamination in about $90 \%$ of EBM samples delivered to NICU infants. Factors related to EBM contamination include hygienic, storage and transport factors.

\section{Data Sharing Statement}

The datasets used and analyzed during the current study are available from the corresponding author on reasonable request. 


\section{Author Contributions}

All authors made a significant contribution to the work reported, whether that is in the conception, study design, execution, acquisition of data, analysis and interpretation, or in all these areas; took part in drafting, revising or critically reviewing the article; gave final approval of the version to be published; have agreed on the journal to which the article has been submitted; and agreed to be accountable for all aspects of the work.

\section{Funding}

The authors received no financial support for the research, authorship, and publication of this article.

\section{Disclosure}

The authors declared no potential conflicts of interest for this work or with respect to the research, authorship, and publication of this article.

\section{References}

1. Rønnestad A, Abrahamsen TG, Medbø S, et al. Late-onset septicemia in a Norwegian national cohort of extremely premature infants receiving very early full human milk feeding. Pediatrics. 2005;115 (3):e269-76. [PMID: 15687416]. doi:10.1542/peds.2004-1833

2. Meinzen-Derr J, Poindexter B, Wrage L, Morrow AL, Stoll B, Donovan EF. Role of human milk in extremely low birth weight infants' risk of necrotizing enterocolitis or death. J Perinatol. 2009;29(1):57-62. doi:10.1038/jp.2008.117. PMID: 18716628. PMCID: PMC2801431.

3. Bergner EM, Shypailo R, Visuthranukul C. Growth, body composition, and neurodevelopmental outcomes at 2 years among preterm infants fed an exclusive human milk diet in the neonatal intensive care unit: a Pilot Study. Breastfeed Med. 2020;15(5):304-311. doi:10.1089/ bfm.2019.0210. PMID: 32298596. PMCID: PMC7360515.

4. Underwood MA. Human milk for the premature infant. Pediatr Clin Nort Am. 2013;60(1):189-207. doi:10.1016/j.pcl.2012.09.008

5. Arslanoglu S, Moro GE, Ziegler EE. The Wapm Working Group On N. Optimization of human milk fortification for preterm infants: new concepts and recommendations. J Perinat Med. 2010;38(3):233-238. doi:10.1515/jpm.2010.073

6. Cossey V, Jeurissen A, Thelissen MJ, Vanhole C, Schuermans A. Expressed breast milk on a neonatal unit: a hazard analysis and critical control points approach. Am J Infect Control. 2011;39 (10):832-838. doi:10.1016/j.ajic.2011.01.019

7. Kapoor D, Jajoo M. Providing expressed breast milk to preterm neonates admitted in an extramural neonatal intensive care unit: where do we stand? Indian Pediatr. 2019;56(12):1051-1052. PMID: 31884438. doi:10.1007/s13312-019-1692-2

8. Nakamura K, Kaneko M, Abe Y, et al. Outbreak of extendedspectrum $\beta$-lactamase-producing Escherichia coli transmitted through breast milk sharing in a neonatal intensive care unit. $J$ Hosp Infect. 2016;92(1):42-46. doi:10.1016/j.jhin.2015.05.002

9. Perez PF, Doré J, Leclerc M, et al. Bacterial imprinting of the neonatal immune system: lessons from maternal cells? Pediatrics. 2007;119(3):e724-32. doi:10.1542/peds.2006-1649

10. Novak FR, Das AV, Hagler AN, Figueiredo AMS. Contamination of expressed human breast milk with an epidemic multiresistant Staphylococcus aureus clone. J Med Microbiol. 2000;49 (12):1109-1117. doi:10.1099/0022-1317-49-12-1109
11. Boo NY. Contaminated milk is a common cause of necrotising enterocolitis: a hypothesis. Malays J Pathol. 2016;38(3):223-227. PMID: 28028291.

12. Weems MF, Dereddy NR, Arnold SR. Mother's milk as a source of Enterobacter cloacae sepsis in a preterm infant. Breastfeed Med. 2015;10(10):503-504. doi:10.1089/bfm.2015.0146. PMID: 26540337. PMCID: PMC4683548.

13. Youssef RF, Darcy E, Barone A, Borja MT, Leggiadro RJ. Expressed breast milk as a source of neonatal sepsis. Pediatr Infect Dis J. 2002;21(9):888-889. doi:10.1097/00006454-200209000-00026 PMID: 12352815

14. Mammina C, Di Carlo P, Cipolla D, et al. Nosocomial colonization due to imipenem-resistant Pseudomonas aeruginosa epidemiologically linked to breast milk feeding in a neonatal intensive care unit. Acta Pharmacol Sin. 2008;29(12):1486-1492. doi:10.1111/j.17457254.2008.00892.x PMID: 19026168.

15. Karimi M, Eslami Z, Shamsi F, Moradi J, Ahmadi AY, Baghianimoghadam B. The effect of educational intervention on decreasing mothers' expressed breast milk bacterial contamination whose infants are admitted to neonatal intensive care unit. $J$ Res Health Sci. 2012;13(1):43-47.

16. Mense L, Rößler S, Hanusch R, Roßberg C, Rüdiger M. Bacterial contamination of mechanically extracted breast milk. Am J Perinatol. 2014;31(4):293-298. [PMID: 23765708]. doi:10.1055/s-00331348028

17. Haiden N, Pimpel B, Assadian O, et al. Comparison of bacterial counts in expressed breast milk following standard or strict infection control regimens in neonatal intensive care units: compliance of mothers does matter. J Hosp Infect. 2016;92(3):226-228. PMID: 26850928. doi:10.1016/j.jhin.2015.11.018

18. Boo NY, Nordiah AJ, Alfizah H, Nor-Rohaini AH, Lim VK. Contamination of breast milk obtained by manual expression and breast pumps in mothers of very low birthweight infants. $J$ Hosp Infect. 2001;49(4):274-281. doi:10.1053/jhin.2001.1117 PMID: 11740876.

19. Nwankwo MU, Offor E, Okolo AA, Omene JA. Bacterial growth in expressed breast-milk. Ann Trop Paediatr. 1988;8(2):92-95. doi:10.1080/02724936.1988.11748547

20. Balmer SE, Wharton BA. Human milk banking at Sorrento Maternity Hospital, Birmingham. Arch Dis Child. 1992. 67(4):556-559. doi:10.1136/adc.67.4.556. PMID: 1580693. PMCID: PMC1793333.

21. Bonacquisti A, Geller PA, Patterson CA. Maternal depression, anxiety, stress, and maternal-infant attachment in the neonatal intensive care unit. J Reprod Infant Psychol. 2020;38(3):297-310. PMID: 31795733. doi:10.1080/02646838.2019.1695041

22. Behari P, Englund J, Alcasid G, Garcia-Houchins S, Weber SG. Transmission of methicillin-resistant Staphylococcus aureus to preterm infants through breast milk. Infect Cont Hosp Epidemiol. 2004;25(9):778-780. doi:10.1086/502476

23. Steele C. Best practices for handling and administration of expressed human milk and donor human milk for hospitalized preterm infants. Front Nutr. 2018;5:76. doi:10.3389/fnut.2018.00076

24. Rodríguez JM. The origin of human milk bacteria: is there a bacterial entero-mammary pathway during late pregnancy and lactation? Advan Nutr (Bethesda, MD). 2014;5(6):779-784. doi:10.3945/ an.114.007229

25. Eglash A, Simon L. ABM Clinical Protocol \#8: human milk storage information for home use for full-term infants, Revised 2017. Breastfeed Med. 2017;12(7):390-395. doi:10.1089/bfm.2017.29047.aje

26. Ukegbu PO, Uwaegbute AC, Ijeh II, Ukegbu AU. Bacterial load in expressed and stored breast milk of lactating mothers in Abia state, Nigeria. Afr J Food Agric Nutr Dev. 2013;13(4):8139-8154. 


\section{Publish your work in this journal}

Pediatric Health, Medicine and Therapeutics is an international, peerreviewed, open access journal publishing original research, reports, editorials, reviews and commentaries. All aspects of health maintenance, preventative measures and disease treatment interventions are addressed within the journal. Practitioners from all disciplines are invited to submit their work as well as healthcare researchers and patient support groups. The manuscript management system is completely online and includes a very quick and fair peer-review system. Visit http://www.dovepress.com/testimonials.php to read real quotes from published authors.

Submit your manuscript here: http://www.dovepress.com/pediatric-health-medicine-and-therapeutics-journal 